DOI 10.37882/2500-3682.2020.06.11

\title{
ГРАНИЦЫ И ПЕРСПЕКТИВЫ ИНСТИТУЦИОНАЛЬНОЙ ТЕОРИИ
}

\section{THE FRAMES AND PROSPECTS OF INSTITUTIONAL THEORY}

\section{Mineev}

Summary: This article offers criticism on the established understanding of the institution and the process of institutionalization as a system designed to regulate human life exclusively by means of rationing, by creation of rules and sanctions for violation of them. Based on the theory of J. Habermas about the separation of "system" and "lifeworld", it is shown that modern institutional theory omits the vast layer in the study of its methodology. Researchers do not pay enough attention to the orientation of the institute. There is no clear understanding of what levels of human existence are influenced by the created institution. The paper characterizes the three main levels of human existence-normative, symbolic and existential, and shows that the study of institutionalization is mainly aimed at the normative and partly at the symbolic levels, while the existential is rarely taken into account and its fundamental significance is not considered.

Keywords: institutionalism, institutional economics, system, lifeworld, institution, rules, levels of human being.
Минеев Матвей Вячеславович

Аспирант, Дальневосточный федеральный университет mineevmatvey@mail.ru

Аннотация: В данной статье предложена критика устоявшегося понимания института и процесса институционализации как системы, призванной регулировать жизнедеятельность человека исключительно средствами нормирования, созданием правил и санкций за отступления от них. На основе теории Ю. Хабермаса о разделении «системы» и «жизненного мира», показано, что современная институциональная теория не затрагивает обширный пласт В изучении своей методологии. В поле внимания исследователей недостаточно сильно сделан акцент о направленности института. Нет четкого понимания, на какие уровни человеческого бытия влияет создаваемый институт. В работе дается характеристика трех основных уровней человеческого бытия - нормативный, символический и экзистенциальный, и показано, что исследование институционализации в основном направлено только на нормативный и отчасти на символический уровни, тогда как экзистенциальный редко берется в расчет и не учитывается его принципиальная значимость.

Ключевые слова: институционализм, институциональная экономика, система, жизненный мир, институт, правила, уровни человеческого бытия.

вершеннее предыдущего и, следовательно, должен был работать лучше [13]. Провал новой системы доказывает, что при конструировании институтов недостаточно ориентации исключительно на нормативный уровень. Также огромное значение имеют коммуникационный и экзистенциальный уровни, которые в данном примере плохо соотносились с новой системой, что и привело эту систему к провалу. Дело в том, что большинство правил, которые работали в старой системе, были основаны на коммуникациях между заинтересованными лицами и главное, на моральных обязательствах и чувстве ответственности.

Дуглас Норт внес существенный вклад в развитии институциональной теории. На его работы опираются многие экономисты и исследователи. Но основная критика идей Д. Норта заключается в неполноте его теории. Он пытается объяснить различные процессы лишь на нормативном (системном) уровне, и абсолютно исключает влияние на систему внутренней мотивации людей, их морали и этики [13].

Таким образом, мы видим, что очень часто не учитывается специфика условий, в которых создается новый институт. Ю. Хабермас назвал такую ситуацию противостоянием между системой и жизненным миром, где часто система подавляет жизненный мир [6]. 
Как итог, можно сказать, что много исследований контролируют лишь верхний, нормативный уровень человеческого бытия. Но существует еще два фундаментальных уровня, которые также сильно влияют на человеческое поведение: коммуникативный и экзистенциальный уровни [10].

В основе нашего исследования границ и перспективы институциональной теории лежат сравнительный и сравнительно-исторический методы, благодаря которым было проведено сопоставление актуальных на сегодня теорий институционализма с другими теориями.

Аналитический и герменевтические методы позволили провести анализ основных теорий и выявить необходимые для работы элементы.

\section{Аополнение к институшиональной теории}

На данном этапе своего развития институциональная теория подвергается широкой критике со стороны различных исследователей. Основная причина такой критики заключается в том, что теория носит системный или нормативный характер.

Один из главных методологов институциональной теории Д. Норт предложил свой вариант понимания того, что такое институт.

В структуре Д. Норта институт - это «правила игры». Институты - это рамки в пределах, в которых люди взаимодействуют друг с другом. Эти рамки включают в себя:

- формальные ограничения в виде правил и предписаний;

- неформальные кодексы поведения, обычаи, привычки.

Также важнейшей характеристикой любого института являются принуждение к выполнению и санкции в случае отклонения от правил [5, с. 12].

Таким образом, Норт делит институт на две части, но при этом обе части обозначает как «правила игры», но правила разной природы.

Формальные ограничения - это правила игры, которые люди создали для комфортного существования.

Неформальные ограничения также являются «правилами игры» установленными людьми. Под неформальными правилами Норт понимает, прежде всего, обычаи, традиции и привычки.

Основная проблема такого подхода заключаются в том, что в сферу анализа не включен принцип разделения понятия на слои человеческого бытия экзистенци- альный, нормативный и экзистенциальный уровни. [10, c. 178]

Взаимодействие между людьми и их существование всегда проходит одновременно на всех этих уровнях, поэтому анализ каждого из них в процессе институционального проектирования является крайне важным.

Мы видим, что институциональная теория в лице Дугласа Норта все же разделяет понимание института на два слоя - нормативный и культурный. Но здесь присутствуют две большие проблемы.

Во-первых, разделяя понимание института на две части, Норт все же объединяет обе эти части, заявляя, что это все «правила игры», установленные людьми для нормального существования.

Во-вторых, разделяя понимание института на два слоя - культурный и нормативный, Норт все же не замечает третий экзистенциональный слой, который представляет собой жизненный мир человека.

В рамки системы или нормативного слоя, помимо формальных правил, попадают также и неформальные. Система всегда структурирует жизненный мир человека, а неформальные правила также структурируют поведение человека, как и формальные. В этом заключается причина объединения Д. Нортом и формальных и неформальных правил в одно целое понятие.

Если взглянуть на понимание института другого крупного методолога, то мы увидим похожую картину. Дж. Ходжсон говорит, что институты - это системы устоявшихся и общепринятых социальных правил, которые структурируют социальные взаимодействия [8, с. 31]. То есть снова, это правила, принятые людьми для создания условий, в которых люди могут существовать с минимальными трансанкционными издержками. Это также отражает нормативный и культурно-символический уровень, но не затрагивает экзистенциальный слой человеческого бытия.

По всему видно, что в среде самых известных институционалистов институт понимается, прежде всего, как нормативная схема, то есть как система, в которой почти нет места жизненному миру.

Именно поэтому сегодня часто можно встретить критику в адрес такого понимания института. Например, McCloskey D. N (2016) замечает, что в работах Д. Норта нет места морали и этики в особенностях поведения людей, попадающих под влияние его институциональной схемы [12, с. 25].

A Ostrom E. и Basurto X. доказывают, что недостаточно 
просто создания надежной механистической схемы института, чтобы он работал. Крайне важно ориентироваться на установки и внутренние правила людей, живущих в рамках институтов [13].

Ввиду вышесказанного, ориентиром для дальнейшего развития институциональной теории должна стать ориентация на поиск баланса между системой и жизненным миром человека, хорошо описанная Ю. Хабермасом в его работах.

В своей работе о теории коммуникативного действия Хабермас выводит центральное понятие, которым является аргументированный дискурс, направленный на понимание между людьми, между которыми установлен единый жизненный мир (жизненное пространство) [7, с. 239]. Достижение понимания возможно исключительно в том случае, если между индивидами установлена коммуникативная рациональность.

Также Ю. Хабермас уделяет большое внимание понятию жизненного мира. Категория жизненного мира нужна для того, чтобы обозначить сферу непосредственного взаимодействия, или сферу практического опыта. Жизненный мир - это мир, складывающийся из интерсубъективных отношений между людьми. Он состоит из действий, языковых конструктов, посредством которых люди категоризируют повседневный опыт и сообщают об этом опыте [9, с. 185].

Юрген Хабермас вводит различение понятий «жизненный мир» и «система» для того, чтобы разделить сферы социального воспроизводства - материальной и символической [7, с. 234].

Символическая система воспроизводства («жизненный мир») - это мир коммуникаций и интерсубъективных отношений между людьми, мир, где воплощаются и реализуются мотивации, потенции и установки человека.

Материальная система социального воспроизводства («система») всегда занимает регулирующую позицию по отношению к жизненному миру. Основная задача системы - это поддержание системного порядка, контроль всего того, что происходит в жизненном мире [6, с. 127].

Таким образом, система и жизненный мир всегда находятся в процессе взаимодействия, более того, система всегда стремится подавить жизненный мир. Именно это мы видим во многих процессах институционального проектирования. И именно такой способ взаимодействия предполагается в теории Д. Норта, которую многие исследователи берут за основу.
Такую дихотомию хорошо описывает цитата Лумана: «Общественное мнение, охраняющее жизненный мир, имеет смысл, отличный от точки зрения государственного аппарата, выражающего интересы системы» [4, с. 443].

Для демонстрации того, как взаимодействует система и жизненный мир, хорошо подходят обыденные примеры.

Существует система образования, в рамках которой всегда должен воспроизводиться системный порядок. Система должна контролировать все процессы, связанные с образованием, чтобы иметь возможность воспроизвести себя в дальнейшем. В рамках этой системы осуществляет свою деятельность преподаватель представитель жизненного мира. У него есть свои личные ценности, связанные с процессом передачи знаний и он лучше всех знает, как эту ценность лучше всего реализовать. Но преподаватель попадает в рамки системы, которая не позволяет его личным ценностям реализоваться так, как он хочет. И преподаватель вынужден подчиниться системе и ее правилам, поскольку система это институт, а одна из главных характеристик института помимо всего прочего это санкции за отход от правил института.

Также ярко подобное взаимодействие заметно на взаимоотношениях между предпринимателем, как представителем жизненного мира, и государством, как представителем системы. Главная ценность предпринимателя - это достижение максимальной прибыли, максимальной полезности и на экзистенциальном уровне это стремление безгранично. Это «выражение деловитости человека, следующего своему призванию» [2, с. 75]. Но система никогда не позволит ему этого сделать, поскольку это вредит самому существованию системы. Поэтому мы видим множество государственных ограничений, налагаемых на бизнес, и особенно на крупный бизнес, например, в виде антимонопольного законодательства.

Итак, мы видим, что отношения между системой и жизненным миром имеет крайне противоречивый характер. С одной стороны, система структурирует жизненный мир и контролирует его хаотическое движение, что приводит к возможности существования и поддержания системного порядка. С другой стороны, система часто сильно давит на жизненный мир и не позволяет ему раскрываться в должной мере.

Сегодня существует тенденция выстраивать институты как запреты, то есть смещать баланс в сторону системы. Эта тенденция вызвана необходимостью поддержания системного порядка. Единственный легальный и безопасный способ его поддержания - это легитимация трансакций. Иначе говоря, это создание бюрокра- 
тической системы, которая по определению является естественной преградой для целенаправленного социального действия [11].

Хабермас также говорил, что весь 20 век ознаменован дисбалансом в сторону системы. Он назвал это колонизацией жизненного мира системами. Этот процесс обусловлен тем, что жизненный мир, будучи причиной движения и противоречий, частично отчуждает себя во внешний мир. Это отчуждение делает его зависимым от социальных структур, а потому вынужден приспосабливаться и подчиняться им. Причину отчуждения он видит в том, что «Место «ложного» занимает «фрагментированное» сознание, которое препятствует просвещению с помощью механизма овеществления» [6, с. 136].

В итоге, мы приходим к простому выводу, что для уменьшения негативного влияния взаимодействия и увеличения позитивного, необходимо держать баланс в процессе влияния институтов на жизненный мир. Единственный способ противостоять системному давлению, это поддержание жизненного мира на должном уровне. Для того чтобы это стало возможным, институциональная теория должна учитывать категорию жизненного мира в процессе институционального проектирования. Но объективно говоря, создание такого баланса маловероятно в ближайшее время, поскольку для этого требуется разорвать прочную связь между властью и капиталом, что пока представить довольно сложно, особенно в России [11].

Таким образом, институциональная теория сегодня интуитивно замечает и включает в сферу своего анализа разграничение между культурным и нормативными слоями, но при этом полностью игнорирует слой экзистенциальный. Теория не отвечает на вопрос почему возникла необходимость создания института? Что на самом деле структурирует институт? Ответ кроется именно в раскрытии экзистенциального уровня человеческого бытия в контексте институциональной теории.

Известный неоинституционалист Дж. Бьюкеннен говорит, что, на «наиболее фундаментальном уровне правила находят свое основание в никогда не иссякающем желании людей жить вместе в мире и гармонии, без непрерывной гоббсианской войны всех против всех» [1, с. 19]. Если еще глубже погрузиться в жизненный мир, то мы увидим, что желание людей жить вместе обусловлено желанием экзистирования, ценностью понимания, которые могут быть реализованы только в обществе Иного, а значит только в институциональной среде.

Можно сделать еще один вывод. Теорией предполагается и много раз обосновывается, что институт структурирует поведение людей, но при этом абсолютно упускается из внимания, что на самом деле институт всегда находится в режиме противостояния жизненному миру людей. Теория Д. Норта замечает только первый мир, но игнорирует другой.

Также, не вполне очевидно, что культурный и нормативный слои могут быть отнесены к институту. Д. Норт считает, что оба эти слоя входят в рамки института по причине того, что оба являются элементами «правил игры» в обществе. Правила же - инструкции, нормативно закрепленные участниками самого института [4, с. 232]. Причина такого закрепления кроется в потребности воспроизводства самой системы. В фирме существует нормативные прописанные правила, позволяющие каждому участнику этого института понимать, как действовать, чтобы эта фирма функционировала подобным образом и дальше. То есть эти правила, всегда направлены на благо этому институту, на то, чтобы он существовал как можно дольше. Чтобы люди, которые, заменят нынешнее руководство в будущем, действовали также во благо этому институту. Поддерживается все это санкциями за отклонение от правил, за попытку помешать воспроизводству данной системы.

Так работают формальные правила. Неформальные правила хоть и не прописаны, но имеют те же законы, что и формальные правила. Институт дружбы также не может обойтись без воспроизводства. Если я не следую некоторым негласным, но основополагающим правилам дружбы, то попасть в дружеские отношения у меня не получится. Следовательно, процесс воспроизводства данного института будет нарушен. Санкцией же за отход от неформальных правил, является то же что и при отходе от формальных правил, а именно, исключение из процесса взаимодействие между субъектами. В случае с фирмой это увольнение из коллектива фирмы, а в случае с дружбой, это ее же отсутствие.

Таким образом, можно согласиться с правотой Д. Норта в объединении формальных и неформальных правил в одно понятие, так как правила не обязательно должны носить только нормативный характер.

Теория институтов объясняет, как и почему люди взаимодействуют, но не объясняет сам корень взаимодействия и причину институтов. Но если бы институциональная теория включила бы в свою методологию категорию жизненного мира, то смогла бы ответить на вопросы о том, почему людей необходимо ограничивать. Почему необходим контроль и санкции за отход от соблюдения правил игры. В. Дементьев пришел к выводу, что общим всех определений и признаков понятия институт выступает одна характеристика - это взаимодействие. Без взаимодействия не работает ни одно определение, а значит и в принципе не существует институтов [3, с. 28].

В конце своего анализа о том, что такое институт, он 
заключил, что для того, чтобы найти ответ на этот вопрос, необходимо ответить на следующий ряд вопросов, и на эти вопросы институциональная теория должна прежде всего направить свой взор. Почему людей нужно ограничивать? Почему для структурирования взаимодействия нужно принуждение? Почему ограничения должны принимать форму правил? Почему институты являются необходимым опосредующим звеном социального взаимодействия? [3, с. 29]

Так вот, жизненный мир, как уже рассматривалось выше, это субстанция, которая постоянно противостоит системе. И если система не будет выстраивать жесткие рамки для этой субстанции, то это будет приводить к дисбалансу всей конструкции в пользу жизненного мира, что так же плохо, как дисбаланс в сторону системы.

В процессе работы было установлено, что многие вопросы, задаваемые институционалистами, проще объяснять через данные методологические основания. Также, разграничение между жизненным миром и системой, позволяет взглянуть на институты, сквозь призму уровней человеческого бытия. Позволяет представить это понятие, в недостающей ранее, структурно-иерархичной схеме. Это означает, что появляется обоснование иерархии признаков понятия институт. На первое место таким образом встают признаки, которые характеризуют институт с позиции ограничительных рамок, созданных людьми. Это говорит об институте, как о реализованном нормативном уровне человеческого бытия. Далее следует говорить о культурно символическом уровне человеческого бытия. Здесь традиции и обычаи реализуются также по институциональной схеме. Это такие же правила игры, за несоответствие которым наступает наказание. Единственное отличие - это не прописанные формально правила. Эти два уровня главенствуют потому, что они позволяют выполнять функцию институтов как процесса воспроизводства общественного порядка. Система потому всегда и давит на жизненный мир, чтобы иметь возможность наиболее качественно выполнять эту свою основополагающую функцию.

Результаты исследования говорят нам о том, что институциональная теория нуждается в серьезной доработке со стороны коммуникативного и экзистенциального уровней человеческого бытия. Наиболее авторитетные ученые, такие как Д. Норт, Дж. Ходжсон, в сфере институционального анализа делают акцент в основном только на самый верхний системный уровень института, оставляя за рамками важнейший вопрос: на что направлен сам институт, что конкретно он регулирует и каковы внутренние законы того, что он регулирует. При этом показано, насколько экзистенциальный уровень человеческого бытия отличается от системного, что означает большую необходимость равноправного анализа обоих уровней в дальнейших исследованиях ученых-институционалистов.

ЛИТЕРАТУРА

1. Бреннан Дж., Бьюкенен Дж. Причина правил. Конституционная политическая экономия. Выпуск 9 серии «Этическая экономия: исследования по этике, культуре, и философии хозяйства» / Пер. с англ. под ред. А.П. Заостровцева. СПб.: Экономическая школа, 2005. 272 с.

2. Вебер М. Протестанская этика и дух капитализма // Избранные произведения: Пер. с нем. /Сост., общ. ред. и послесл. Ю.Н. Давыдова; Предисл. П. П. Гайденко. - М.: Прогресс, 1990. 808 с.

3. Дементьев В.В. Что мы исследуем, когда исследуем институты // Terra Economicus. 2009. Тoм 7, N1, 2009. С. 13-30.

4. Луман Н. Социальные системы. СПб.: Наука, 2007. 643 с.

5. Норт Д. Институты, институциональные изменения и функционирование экономики/Пер. с англ. А.Н. Нестеренко; предисл. и науч. ред. Б.3. Мильнера. М.: Фонд экономической книги «Начала», 1997. 180 с.

6. Хабермас Ю. Отношения между системой и жизненным миром в условиях позднего капитализма / Пер. с нем. В.И. Иванова // THESIS: теория и история экономических и социальных институтов и систем. 1993. Т. 1., Вып. 2. М.: Начала-пресс, 1993. С.123-136.

7. Х Хабермас Ю. Теория коммуникативного действия // Вопросы социальной теории. 2007. Том 1, Вып. 1. С. 218-264.

8. Ходжсон Дж. Экономическая теория и институты. М.: Дело, 2003, 464 с.

9. Щюц А. Избранное: Мир, светящийся смыслом. Пер. с нем. и англ. М.: «Российская политическая энциклопедия» (РОССПЭН). 2004. 1056 с.

10. Ячин С.Е. Аналитика человеческого бытия: введение в опыт самопознания. Систематический очерк. М.: НИЦ ИНФРА-М, 2014. 210 С.

11. Ячин С.Е. Теория бюрократии в свете реалий современной России // Ойкумена. 2015. N 1. С. 42-57.

12. McCloskey, D.N. Max U versus Humanomics: a critique of neo-institutionalism // Journal of Institutional Economics. 2016. N 12(1). P. 1-27.

13. Ostrom E., Basurto X. Crafting analytical tools to study institutional change // Journal of Institutional Economics. 2011. N 7(3). P. 317-343.

(с) Минеев Матвей Вячеславович (ineevmatvey@mail.ru ).

Журнал «Современная наука: актуальные проблемы теории и практики» 